\title{
Magnitude, causes and management of avoidable blindness: A cross-sectional study in Pravara Rural Hospital of Rural Medical College, Maharashtra, India
}

Shubhada Avachat ${ }^{\prime}$ Suchit Kamble ${ }^{2}$, Deepak Phalke ${ }^{3}$, Surekha Bangal ${ }^{4}$ Mrinal Zambare $^{5}$

${ }^{1}$ Assistant Professor; ${ }^{5}$ Professor and Head; Department of Preventive and Social Medicine, Padmashri Dr. Vitthalrao Vikhe Patil Foundation Medical College, Ahmednagar, India. ${ }^{2}$ Associate Prof KVM Medical College, Sullia, Karnataka, India. ${ }^{3}$ Professor and Head, Department of Preventive and Social Medicine; ${ }^{4}$ Professor and Head, Department of Ophthalmology; Rural Medical College, Loni, India.

\section{Abstract}

There are an estimated 180 million people worldwide who have a visual impairment. Out of that number, nearly 45 million are blind and four out of five of them live in developing countries. One-third of the world's blind people (15 million) and $50 \%$ of the world's blind children ( 0.7 million) live in the South-East Asia Region. Approximately $90 \%$ of all the cases of blindness in this region are avoidable. The present study was conducted in a tertiary health center, Pravara Rural Hospital of Rural Medical College Loni, Maharashtra, India, to examine the magnitude of preventable causes of blindness and to investigate the various causes responsible for blindness along with treatment offered. Out of 703 patients examined in the ophthalmology department in January 2011, 588 (83.6\%) patients had avoidable blindness 525 from the outpatient department and 63 from the inpatient department. The Most common cause was cataract (60.95\%), followed by refractive error (26\%), whereas vitamin A deficiency and retinopathy were least common causes of avoidable blindness in our study. The baseline data presented by the present study about magnitude, causes and management of avoidable blindness will help to make 'Vision 2020' successful.

Key words: Avoidable blindness, Rural area, Tertiary health center, India.

\section{Introduction}

Visual impairment and blindness due to ocular disease is a significant public health problem in the many parts of the world including India. An estimated 180 million people worldwide are visually disabled, of whom nearly 45 million are blind, four out of five of them living in developing countries ${ }^{1}$. As far as the South-East Asia Region is concerned, one-third of the world's blind people (about 15 million) and $50 \%$ of the world's blind children (approximately 0.7 million) live in this Region and $90 \%$ of this blindness in the Region is avoidable. ${ }^{2}$ Blindness is one of the most significant social problems in India. According to the National Survey on blindness 2001-02, the prevalence of blindness in population 50 years and above was $8.5 \%$ and estimated prevalence in general population was $1.1 \% .{ }^{3}$ Over $90 \%$ of the 12 million blind people in India are living in the rural areas, most of whom are most likely to unserved and unreached by healthcare services. ${ }^{4}$ The concept of avoidable blindness (i.e. preventable and curable) has gained increasing recognition in recent years. Avoidable blindness is defined as blindness (visual acuity less than 3/60) which could be either treated or prevented by known and cost effective measures. ${ }^{5}$ Main causes of avoidable blindness are cataracts, refractive errors, childhood blindness including

\section{Practice points}

- In South-East Asia Region, $90 \%$ of blindness is treatable and avoidable.

- The present study shows that a higher prevalence $(83.6 \%)$ of patients was suffering from avoidable blindness in a tertiary hospital based in a rural area of India.

- Senile cataract was the most common cause followed by refractive error and both the causes are treatable and avoidable.

- Findings will help to develop and implement appropriate programs to prevent blindness.

- Large-scale studies are needed to identify the magnitude of the about avoidable blindness and their effective management to make 'Vision 2020' successful.

congenital cataracts etc. It has been estimated that blindness costs the world $\$ 25$ billion annually in lost productivity. The cost is three times higher if the cost of rehabilitation care

Correspondence: Dr. Mrs. Shubhada Avachat, Samartha colony, Bhutkarwadi, Ahmednagar, Maharashtra 414003, India. E-mail: shubhadasunil@gmail.com, ssavachat@rediffmail.com. 
givers is included. Therefore a global initiative has been taken to eliminate avoidable blindness by the year $2020{ }^{6}$ India is committed to the goal of elimination of avoidable blindness by 2020 - which is in line with 'Vision 2020'. 'Vision 2020' is a global initiative for the elimination of avoidable blindness, a joint program of the World Health Organization (WHO) and the International Agency for the Prevention of Blindness (IAPB). ${ }^{7}$

Understanding the causes and demographic variables associated with visual impairments and their association with treatment seeking behavior in addition to barriers to eye care in rural area of India is important ${ }^{8}$. To eliminate avoidable blindness in India, all the components of disease control like surveillance, infrastructure development, and human resource management must work efficiently. It is also necessary to conduct relevant research to obtain valid and reliable data on causes and magnitude of blindness and effectiveness of eye care delivery system in the country. The aim of this study was to examine the magnitude, causes and management of avoidable blindness in Pravara Rural Hospital of Rural Medical College Maharashtra, India.

\section{Materials and Methods}

A cross-sectional, retrospective and record-based study was conducted in Pravara Rural Hospital of Rural Medical College Loni, Maharashtra, India. The study area is a rural area in Ahmednagar district of Western Maharashtra where majority of population is engaged in agricultural work. All the patients who attended ophthalmology outpatients department (OPD) and admitted in ophthalmology wards of Pravara Rural Hospital Loni from $1^{\text {st }}$ January 2009 to $31^{\text {st }}$ January 2009 were included in the study. Total number of patients was 703, out of which 625 were OPD patients and 78 were indoor patients.

After obtaining necessary permission from the concerned authorities, the case records of the individual patients were obtained from the Medical Records Department of Pravara Rural Hospital. Case records prepared by faculty members of ophthalmology Dept were studied in detail by the author and first co author. Each case record was studied and the cause and treatment given for the individual patient was recorded. The magnitude of avoidable causes of blindness and its classification was done as per guidelines discussed in the literature. ${ }^{4-6}$

\section{Results}

Out of 703 patients examined in ophthalmology department (both outpatients and inpatients departments), 588 (83.6\%) patients had avoidable blindness. The number patients with avoidable blindness in outpatients and inpatients departments were 525 and 63 respectively. Analysis of cases was done according to causes and magnitude. Most common cause was cataracts followed by refractive errors whereas vitamin A deficiency and retinopathy were least common causes of avoidable blindness (Table 1). Out of 525 OPD patients, $320(61 \%)$ patients had cataracts among them $205(64.1 \%)$ had immature senile cataracts and 109 $(34.1 \%)$ had mature senile cataracts and $6(1.9 \%)$ had congenital cataracts. While among indoor patients, 23 (51.1\%) had immature, $21(46.7 \%)$ had mature senile cataracts and $1(2.2 \%)$ had congenital cataracts. The patients were operated by following procedures: extra capsular cataract extraction $18(40 \%)$ small incision cataract surgery $10(22.2 \%)$ and phacoemulsification $17(37.8 \%)$. All the patients treated for cataract were given intraocular lens implantations.

Table 1: Magnitude of avoidable causes of blindness in outpatients and inpatients departments

\begin{tabular}{|l|c|c|}
\hline Causes & \multicolumn{2}{c|}{ Number of patients } \\
\hline Outpatients & Inpatients \\
\hline Refractive error & $45(71.4 \%)$ & $320(61 \%)$ \\
\hline Corneal ulcer/opacity & $12(19 \%)$ & $33(6.3 \%)$ \\
\hline Glaucoma & $4(6.4 \%)$ & $15(2.9 \%)$ \\
\hline Diabetic Retinopathy & $2(3.2 \%)$ & $8(1.5 \%)$ \\
\hline Hypertensive Retinopathy & - & $6(1.1 \%)$ \\
\hline Vitamin A deficiency & - & $2(0.4 \%)$ \\
\hline Total & 63 & 525 \\
\hline
\end{tabular}

Refractive error was present in 141 (26.9\%) OPD patients myopia and presbiopia were the two commonest refractive errors observed among the study population (Table 2). Corneal opacity/ulcer was present in $6.3 \%$ of OPD and in $19 \%$ patients admitted in hospital. Glaucoma was present in $2.9 \%$ of OPD patients while in $6.4 \%$ patients admitted in the ophthalmology wards were suffering from glaucoma. Diabetic retinopathy was present among 8 (1.5\%) OPD patients and $2(3.2 \%)$ admitted patients. They were treated by oral hypoglycemic drugs and insulin, depending on their glucose levels. Laser photocoagulation was advised for one patient. Hypertensive retinopathy was seen identified in 6 OPD patients and antihypertensive drugs were prescribed for them. Two patients with uncontrolled hypertension were referred to superspeciality hospital for further management. Ocular manifestations of Vitamin A deficiency were seen only in $2(0.4 \%)$ OPD patients.

Table 2: Distribution of outdoor patients having refractive errors $(n=141)$

\begin{tabular}{|l|c|}
\hline Refractive errors & No of patients \\
\hline Myopia & $58(41.13 \%)$ \\
\hline Presbiopia & $52(36.8 \%)$ \\
\hline Hypermetropia & $21(14.8 \%)$ \\
\hline Pseudophakia /Aphakia & $10(7.1 \%)$ \\
\hline Total & 141 \\
\hline
\end{tabular}




\section{Discussion}

In the present study, we found high prevalence (83.6\%) patients suffering from avoidable blindness in a tertiary hospital based in a rural area in India and cataracts (61\%) was the most common cause of visual impairment. Rapid Assessment of Avoidable blindness conducted in 20062007 in India under the National Blindness Control Program also identified cataracts $(62.6 \%)$ as the main cause of avoidable blindness. ${ }^{10}$ Similarly, study conducted by Thulasiraj and Nirmalan ${ }^{11}$ also found cataract as the most common cause of blindness in rural area of South India. From these studies, there emerges a strong need for effective programs in India to realize the goal of the 'vision 2020'.

Visual impairment due to uncorrected refractive error has immediate and long-term consequences in children and adults $^{12}$. In our study, out of 525 OPD patients 141 (26.9\%) patients had refractive errors and myopia; presbiopia were the commonest refractive errors. As mentioned in Global Report, 153 million people were estimated to be visually impaired due to uncorrected refractive errors and the prevalence of uncorrected refractive error was almost $20 \%$ among adults $>50$ years $^{12}$. Data from the Andhra Pradesh Eye Disease study showed that refractive errors constituted $12.5 \%$ of the blindness and $59.4 \%$ of the visually impaired. ${ }^{13}$ The magnitude of corneal opacity in our study was $6.9 \%$, more common than glaucoma (2.9\%), which was similar to the study conducted by Khandekar and Riyami, ${ }^{14}$ in which the prevalence of glaucoma and corneal opacity was $3.1 \%$ and $6.8 \%$ respectively.

\section{Conclusion}

This study identified a higher number of patients who were suffering from avoidable blindness in a tertiary hospital based in a rural area of India. Senile cataract was the most common cause followed by refractive error and both the causes are treatable and avoidable. The baseline data of this study about magnitude, causes and management of avoidable blindness will help to develop and implement appropriate programs to prevent blindness. Large-scale studies should be conducted in South-East Asia Region to identify the magnitude of the avoidable blindness and implement effective programs to make 'Vision 2020' successful.

\section{References:}

1. Resnikoff S, Pascolini D, Etya'ale D, Kocur I, Pararajasegaram R, Pokharel GP, Mariotti SP. Global data on visual impairment in the year 2002, Bull World Health Organ 2004;82:844-85.
2. WHO. Health Situation in South East Asia Region, 1998-2000. New Delhi: World Health Organization, 2002.

3. Kishore J. National Programs of India. 6th edition. New Delhi: Century Publications, 2006.

4. Vision 2020 India. About VISION 2020: The Right to Sight INDIA Forum. Gurgaon, Haryana: Vision 2020 India, 2008.

5. Pizzarello 1, Ablose A, FlytcherT. Vision 2020. The Right to Sight: A Global initiative to eliminate avoidable blindness working together to eliminate avoidable blindness. Arch Opthalmol 2004;122:61520.

6. Park K. Park's Textbook of Preventive and Social Medicine. $20^{\text {th }}$ edition. Jabalpur: Bhanot Publishers, 2009.

7. WHO. Global Initiative for the Elimination of Avoidable Blindness: action plan 2006-2011. Geneva: World Health Organization, 2007.

8. Jose R, Rathore A. Salient features of National Program on Blindness during the XIth five year plan. Indian $J$ Opthalmol 2009:57:339-40.

9. Vilas Kovai, S. Krishnah. Barriers to accessing eye care services among visually impaired population in rural Andhra Pradesh South India. Indian J Ophthalmol 2007;55:365-71.

10. Jose R, Rathore A. Community Ophthalmology: Revisited. Indian JCom Med 2010;35: 356-8.

11. Thulasiraj R, Nirmalan R. Blindness and visual impairment in a Rural South Indian Population. The comprehensive eye survey. Ophthalmol 2003:110;1491-8.

12. Resnikoff S, Pascolini D, Mariotti SP, Pokharel GP. Global magnitude of visual impairment caused by uncorrected refractive errors in 2004. Bull World Health Organ 2008;86:63-70.

13. Dandona L, Naduvilata T. Is current eye care policy focus almost on cataract is adequate to deal with blindness in India? Lancet 1998;351:1312-6.

14. Khandekar R, Riyami A. Prevalence of determinants of blindness, low vision among elderly Omani Population. Indian J Ophthalmol 2010;88:313-9. 